\title{
DESIGNED TO INSPIRE, DISRUPT AND TRANSFORM: REFLECTIONS ON IO YEARS OF THE GRADUATE DIPLOMA IN SUSTAINABLE PRACTICE
}

\author{
Alexa Forbes and Steve Henry
}

\section{INTRODUCTION}

This article presents a personal account reflecting the experiences of the facilitators of a start up graduate programme at Otago Polytechnic (OP) New Zealand over the period 2009-2019. The Graduate Diploma Sustainable Practice (GDSP) was developed to reflect the institution's prioritisation and embedding of sustainable practice into its operations and curriculums. A previous article reflected the detail of the programmes, research and consultancy that occurred (Henry \& Forbes, 2017a). This article brings the authors' and learners' voices into a form that is evocative to offer insight into how learning was designed, delivered and experienced. Over the 10 years, the programme has transformed from exploring sustainable practice into exploring sustainable practice as a pivot point into regeneration. The programme's nature too has transformed to become generative and emergent. In this Collaborative Autoethnography, the authors seek to present an emotional account of their change of meaning over time (Bochner \& Ellis, 2016).

The authors are motivated by gaining fresh insight which can result in their improved practice as facilitators of programmes designed to inspire, disrupt and transform. The authors' curiousity stems from the following questions:

- How can disruptive programmes have a licence to operate in risk adverse insitutions?

- How can learner transformation (leaps in learning rather than incremental change) be designed for?

As we progressed through a decade of delivering sustainable practice programmes, it became more and more evident that the word 'sustainability' had become a buzz word in the general public lexicon. This led to definition difficulties, what actually is sustainability and hence sustainable practice? While this question is out of scope for this paper, it was increasingly asked over the years and led to these programmes becoming more and more reflective as people dug inside themselves to understand their connections to their natural world and their relationships as part of that world. This led to an emotional journey for many learners which is why we have taken this particular methodological path.

Following the research phase, both authors wrote individually then shared drafts ahead of merging together in this manuscript. This method was chosen because of the deep emotional journey of reflection in the shared pathway of delivering these programmes.

The article provides a narrative constructed by both authors to bring a range of aspects into consideration. This is the main body of the text. The authors' voices are indicated by their names. Learners' voices are italised and centralised. Learner voices were gathered from a survey sent to the last known email of all 78 graduates 
asking learners to reflect on their experience of the programme. Twenty responses were received. In addition, 15 people attended three focus groups. The voices were gathered from the written response and what focus group participants said. Ethics approval was gained to collect and publish these voices anonymously.

\section{CONTEXT}

In 2008, Otago Polytechnic made a 'Simple Pledge' to "embed sustainable practice into all we do" (Otago Polytechnic, 2008). At the time, this was the only public learning institution in Australasia to commit to such a pledge. In time, there was demand from business, government and communities to learn how to deliver sustainable leadership because, as OP found, the pledge might be simple, enacting it was not.

OP wanted to lead sustainable practice education so there was significant senior executive support for the new programme. Steve Henry had been employed in 2006 to lead a culture shift that would embed sustainable practice into all OP's programmes. He was co-author of the Pledge. A timely $\$ 100,000$ gift to OP to develop sustainable practice qualifications gave courage to design something very different, particularly as current efforts had not delivered sustainability education (Sterling, 200I). The focus turned to developing a programme that might inspire, disrupt and transform.

Steve: We knew incremental change in sustainable practice was not sufficient - we sought leaps and transformation. As we do not make transformative change without shifting our frames of reference (Mezirow, 1997) we knew there would be challenges. But we had a license to innovate, and were encouraged by our Chief Executive to be bolder. We knew education of a different kind was needed - one that takes us to the heart of things (Schumaker, 20II). The opportunity to embed this work in a public institution rather than private consultancy was rare. I am so glad I took it. A team designed the qualifications with learners' real projects at the centre, measured against sustainable outcomes. Projects were mapped using system thinking tools, success beyond financial was defined, then suitable strategies and action were designed, implemented and evaluated. Accurate audit tools meant learners were often painfully confronted with the knowledge that their dream project was neither socially nor ecologically sustainable. So learners faced change. What they did with that was the essence of the programme. Facilitating such a programme was exhilarating. I became programme leader. I was hooked by the possibility.

The model was designed to deliver real projects while doing research and actual consultancy work. Real projects brought by learners would work alongside national and regional projects led by the staff team. These included calculating New Zealand's Ecological Footprint, piloting biodiesel in Queenstown and facilitating community-led development amid rapid tourist growth.

The programme was articulated as a way to "gain the knowledge to promote and implement sustainable leadership in your community and workplace. Examine the social, economic, political and environmental implications of sustainability..." (Otago Polytechnic, 20I0).

This course was nothing short of life changing. What began as a career reset ended up in complete change of direction and opening of possibility.

Learning to think in systems serves me every day.

Alexa Forbes was a Queenstown-based public relations consultant initially contracted in 2010 to run a marketing campaign for a new graduate programme in sustainable practice. 


\begin{abstract}
Alexa: It was a very difficult thing to articulate although there was lots of interest, including my own. I enrolled in 2012. By 2013, I had sold my PR company and was working part time for the then Centre for Sustainable Practice delivering a community engagement contract for the Queenstown Lakes District Council using a framework for sustainable development. This was the logical extension of my student project (Henry \& Forbes, 2017b). I was eventually contracted as a programme facilitator and continued my own transformation through a Masters then a Graduate Diploma in Tertiary Education. I am contributing here as a facilitator so none of the learner comments are mine.
\end{abstract}

\title{
A DIFFERENT DESIGN
}

The programme design focused on learners customising how they wanted to use the programme. If they had a clear project in a workplace then that became the focus. If they were unsure then learners could support others' projects until they became clear. Being a peripheral observer is a powerful learning and on-boarding method (Lave \& Wenger, 1991). There were no campus classes, we gathered online. The technology wasn't great initially in 2011, but at last we could include anyone who lived anywhere. Optional learning intensives (two sessions of three days each year) provided physical connection. Some learners attended none, some all.

Steve: The fluid nature of the programme ensured learners were constantly challenged. This was intentional. A disorientating dilemma is seen as a precursor to learner transformation (Mezirow, 2000). When someone thought they had clarity there was always another layer of enquiry. The role of facilitators was to ensure a level of discomfort - to find that learning edge. When learners showed their edge to each other, it brought deeper inquiry, usually emotionally. 'Why is this project so important to me?' became the hidden curriculum. We varied the locations of intensives so we could visit each other's projects first hand and create opportunities for experiencing the unexpected.

Alexa: As a facilitator, I was learning, from Steve, from the learners, from the institution. This stage of my learning brought a dawning understanding that all learning is based in and shaped by our deep culturally informed values.

I went exploring down project rabbit holes and had to be reluctantly pulled out from them to not drown in the detail.

I began with a fixed idea and ended up in a completely different place I would never have expected... It wasn't what I was expecting. It was unconference style learning. It's what I needed.

\section{THE POWER OF RETREAT}

The creation of community on-line happened, surprisingly. It was evidenced by expressions of joy and whanaungatanga that emerged at every intensive. People who had never met in person found their relationships were in place. It was quite weird to experience. Sometimes people were very different in the flesh, sometimes exactly as expected. Again, thinking and judgement were suspect - not to be relied on. The intensives were intense. Packed with learning, full noise ako. We realised that if we could bring people together once or twice a year, we could maintain the relationships online throughout the rest of the year. Intensives were carefully planned, but included huge flexibility. The power was in giving learners control over their own explorations, our planning was mostly invisible.

Learning intensives were the juice of the programme for me - the most valuable learning at so many levels.

You are so much shorter than I imagined! 


\section{RESILIENCE IN POVERTY - EXPERIENTIAL LEARNING}

North Island learning intensives from 2012 to 2015 were intentionally held rurally in a setting with no electricity, compost toilets, simple cabin accommodation and food harvested from the land. Most participants were middle class Pākeha, so it felt like camping yet there was an important enquiry at play - could we live like this all the time? In the rain and the wind? The 10-hectare land we were based on, in Turangi, had food resilience. There were over 350 fruit and nut trees and gardens that today feed 100 kids at school every day. Lunch was "go and find it" and meet back here to share. To experience food in such abundance highlighted the truth of urban industrialized food systems more eloquently than any lecture. We cooked in steam or in a rocket stove - a type of stove with net zero carbon emissions. The generosity and trust to just go and see what you find, is rare among land owners. Awhi farm in Turangi is a remarkable piece of infrastructure for learning. Lisa Isherwood, Tüwharetoa, can track 26 generations on this land (whakapapa) which is owned by a Māori trust. There was a level of unspoken awe as those who visited glimpsed a collaborative ownership model so different from the norm.

The learning intensives at Awhi farm blew my mind.

Experiencing connection to the land and simplicity of living modelled, changed my mindset.

Awhi farm was a place of deep healing for me - it reconnected me to land.

Using a compost toilet was confronting.

I saw happiness amid material poverty so saw wealth in a new light.

I was thinking: Why are we doing weird stuff? Because it was so raw and new, it was energised. It was really quirky - challenging.

Steve: By experiencing connection through simplicity of good design of land use and food systems, learners understood the normalisation of commercialised land and food systems. We were like kids exploring a new frontier - frontiers of perspective. What initially appeared to be poverty was wealth. Paradox. I considered leaving the programme in 2013 - burn out. I spent nine months living at Awhi farm in 2013-14 as a way to cope with being. Professionally, I went from holding a narrative of "clever expert" to an "enquiring facilitator". It was such a relief to show up without the answers, but with questions. It added a lot more value to learners. This coincided in sharing facilitation on the programme with Alexa. I recognised, and moved on from, my founder's syndrome. I realised the programme could only develop if it was not dependent on me. The irony was palpable as this is what I had been saying to learners for so long - can you design your project to operate without you? I now knew the programme could operate without me.

Alexa: What is poverty? What is wealth? Once the foundation of our 'normal' land and food systems were challenged, what else could be? Everything.

\section{TE AO MĀORI}

In 20II, we had curiosity, but little true regard for Te Ao Māori. This started changing with our relationship with Awhi farm, and also as consultation with the office of the Kaitohutohu at OP became compulsory in all degree level courses. We were gently nudged toward a wider view of the world. Alexa began learning Te Reo Māori in 2015 as and when courses became available in Queenstown. In 2021, she finished her Level 5 but is still working on recognising and stripping back her colonialism. Recognising Māori has been unsettling, disorientating but ultimately enriching and grounding. We bring this to our learners, not as experts, but as learners ourselves - ngā manu hou - the new birds. Transformation is occurring to us and our community and it is based in four pou: Whanaungatanga, Manaakitanga, Kaitiakitanga and Ako. 
Whanaungatanga in our practice: Establishing community, creating an environment and practice that invites people to bring their whole selves and be present - based in Mason Durie's model of Te Whare Tapa Wha (Durie, 1998). Relationships to everything, are everything.

Manaakitanga in our practice: Upholding the mana of every individual, ensuring respect for their position. Making it safe for views to be challenged and beliefs shaken.

Kaitiakitanga in our practice: Looking after people. Guarding their rights to their feelings and values. Respect for their narratives. Being reliable and ensuring the values of the institution are upheld as learners take responsibility for their own learning. Setting up frameworks for people to explore within.

Ako in our practice: We as facilitators are not expert in our learners' learning. We support, but we also learn from learners. We learn in community, it is a social activity. We respect everyone's knowledge. Learning is shared up and down the power structure - tuakana /teina relationships. He kākano - a seed. From somewhere, full of potential to become.

Intersectional lens: looking at an issue from its systemic structures. Lenses of racism, sexism etc. We were looking at things from privilege perspective. We weren't grounded in the issues of race or other intersectional lenses.

\begin{abstract}
Alexa: "E kore au e ngaro, he kākano i ruia mai i Rangiātea" Māori whakatauki loosely translated as; I will never be lost, I am a seed descended from Rangiātea. "A long-lived overstory can dominate the forest for generations, setting the ecological conditions for its own thriving while suppressing others by exploiting all the resources with a self-serving dominance. But, all the while it sets the stage for what happens next and something always happens that is more powerful than that overstory: a fire, a windstorm, a disease. Eventually, the old forest is disrupted and replaced by the understory, by the buried seedbank that has been readying itself for this moment of transformation and renewal" (Kimmerer n.d.). I also learned from Wall Kimmerer that science is not as rational as I had been taught and the observation cannot be independent from the observer. He mihi atu ki a koe! Māori studies from Te Tiriti acquainting, through to Te Ao Māori and and Te Reo Māori - have slowly shown me how much of how/what I think, know and do is within the context of that overstory.
\end{abstract}

Steve: How naive I was and am naive regarding matters of Te Ao Māori. There is much to learn.

\title{
TRANSFORMATIONAL LEARNING
}

To support learners to think in systems and not get overwhelmed, staff invited learners to frame and reframe their projects. Key frameworks were used to measure sustainable practice or change capability. Staff introduced critical autoethnography and wayfinding as methods to map their journey of meaning-making. What am I in relationship to the chosen project and how have I changed?

The programme was set in a context of enabling change to meaning-making structures for each person. If learners were unable to drop their assumptions, the programme became challenging and confronting for them. Those learners who withdrew were generally unable to cope with the diversity of other learners or with the confrontation of their own changing narrative.

Disorientation is considered a cornerstone condition of transformational learning and how learners respond to challenges to their traditional frames of reference (Mezirow, 2000) is key to their breakthrough success. When a learner was blinded by passion for their project, there was a loss of criticality. Often the passion projects were immense, such as an audit of the sustainability of New Zealand or a suitable response to climate change or the establishment of a business. 
Steve: Some learners resisted change. They wanted learning about sustainable practice knowledge and not too much, thank you. They were catered for, yet on the whole attended fewer learning intensives and class sessions. Of the 78 graduates, approximately one in three made it clear they were there for professional change not personal change. I am not convinced one can happen without the other.

Alexa: Sustainability for me starts with the internal work of recognition and acknowledgement of values and culture. Often this includes a period of grief when the understanding of human systemic damage comes into focus. Until I understood my own ways of believing and understanding, sustainability was an external concept. Once I could allow an internalisation of sustainability, even when it contradicted other beliefs, much more became possible. Frameworks help people to operate from wherever they are, and to access true thinking while avoiding overwhelm. Frameworks also help people keep the concept externalised, if they so wish, as they head down the professional change pathway without having to peer too deeply into themselves.

The FSSD [framework for strategic sustainable development], four principles. Backcasting image.

I've brought it out over the years. If someone's struggling with something, it's easy to map the system. If someone is leaping straight to solutions, can apply this to pull them back from solutions and think stuff through.

\section{ON SKINNY DIPPING}

On a hot February day in 2012 in Wanaka, Central Otago, a group of 12 learners had spent two hours visiting a farm focused on what is now called regenerative agriculture during a learning intensive. As we drove past the lake, someone said "let's go for a swim." Within minutes, a group of women and a group of men were in the water, some wearing something and some wearing nothing. The genders were apart, together and some did not swim. There was laughter and relief at the heat.

Fast forward to 2018, in Coromandel at Karuna Falls, an intentional community of some forty years, a group of 12 learners at a learning intensive were swimming in the water hole in the February heat. Everyone wears togs and one, born and raised in that community said "this is the first time I have ever worn togs in this pool." The group had agreed to wear togs so everyone felt comfortable to participate and because the risk of offence in a formal learning programme was too high to be nude together.

Steve: These incidents may not seem a big deal, but they raise the dilemma of the behaviour of a group of adults in a formal learning community. Where does the institutional responsibility start and stop? At the time Otago Polytechnic used the 'front of the paper' test for such dilemmas - how would this look if it was presented by media in a critical light? The 2012 incident showed how casual and naive we were, the 2018 one how we made an important choice of inclusion.

Alexa: Something lost, something gained. Social and institutional norms add a layer of safety by maintaining a reliable expectation. I've learned that this is ok, because my culturally formed norms are not the same as everyone else's but it's important all situations are safe for whoever has entrusted us with their learning environment. We were unable to cater for the level of diversity we might have liked - that had to be accepted. Inclusion is a core belief of mine, but inclusion at extreme ends of norms means exclusion for others - paradox.

The retreat course in the Coromandel was one of the most significant learning experiences of my life - I had experiences that were unexpected and conversations and thought and felt in a way I had never before. 


\title{
ON ADHERING TO INSTITUTIONAL POLICY
}

The brief for the GDSP was to provide new insights into the integration of ecology with social, cultural and financial success. We believed this required a transformational mindset (Mann et al., 2017) which was not welcomed by all senior managers at the institution. One senior executive was clear that we should innovate, then act, and request forgiveness if needed. Another executive questioned the quality control yet could not argue with the learner feedback as exemplary. By 2016, an executive asked "why do we keep trusting you?" following two complaints that year from learners not getting what they expected. As a publically funded course, we were expected to take anyone who had a degree or equivalent. A willingness to change was the biggest tension and constraint to learning.

Steve: We had a trusting manager who was delighted with the programme, but knew little of the detail of learning intensives and their intentional design to challenge. A new policy of risk management for every offsite facility meant going to Awhi farm became very difficult as no building there was code compliant. What if there was a fire or earthquake? We stopped going for this reason. A small tragedy to avoid fear of a bigger one. Some learners wanted knowledge to change systems rather than being personally involved in any change, others wanted transformation as a career reset. Attempting to meet this need was difficult. We created a scale from I to 10 for those with fixed $(1)$ or flexible mindsets $(10)$. It was sad to me we could not cater for all. In 2012, we had learners from range 2 to 9 and by 2016 we realised the course could only cope with a range of 3 to 7 if it was to survive a risk averse institution.

\begin{abstract}
Alexa: An institutional level of behaviour that can be relied on makes for a safe institution. If we go outside of that, it's not safe for everyone because people rely on those levels. While it was challenging to not be in control of those levels, l've discovered that transformational learning is well possible within the boundaries of a national institution. Our job is to ensure learners have the tools and space to investigate, recognise and judge their own values and assumptions. Institutional norms are surprisingly no barrier to disorientation and transformation.
\end{abstract}

Transformational - get my own house in order first before working on the business idea. Discovery and rawness was a part of it....

$[\mid t]$ opened a diverse way of applying thinking.. There are many ways to apply the thinking, not just environmental. Applies to every aspect of life.

\section{THE FUTURE}

By 2016, paradoxes in the taught programme became untenable. Taught courses were too inflexible to deliver transformational outcomes - prescription was an enemy of transformation. We moved to Capable NZ - a part of OP's College of Work-Based learning where experienced practitioners unpack their learning for credit in degrees. This suited the GDSP because more transformational learning is possible when the whole qualification learning outcomes are assessed rather than individual courses (Ker, 2017) and learner-centric programming needed flexibility.

By 2021, the programme was superseded by the Graduate Diploma in Professional Practice (Sustainable Practice) which gives learners more autonomy to focus on their practice capabilities such as leadership and change rather than be over-focused on specific 'courses' that may or may not be relevant. The future is a maze of complex challenges and a programme that requires reflection and critical thinking skills builds the resilience needed to address those challenges. We recognise the need to move from passion projects of individuals to established communities of practice where learners work with stakeholders towards solving challenges. This will need a structure that helps us move people from rigid positioning and into deeper understanding that supports 
collaboration and finding unknown capability. It also needs vertical integration of courses. We are committed to bicultural expression through the programme. Working as a Treaty of Waitangi ally underpins this process.

Steve: The move to assess at whole of qualification level means learners have more autonomy in their projects. Capable NZ processes have given us a structure to work within that we can work within.

Alexa: Resilience and biculturalism are the ways of being that will serve us well into the future. We have learned much through our mistakes and the guidance of others.

\title{
CONCLUSIONS
}

We return to the earlier questions:

- How can disruptive programmes have a license to operate in risk adverse insitutions?

- How can learner transformation (leaps in learning rather than incremental change) be designed for?

For a licence to operate when pushing boundaries, there needs to be constant buy-in from all stakeholders, especially the most senior decision makers. The value and impact needs to be continuously articulated for any programmes that is pushing boundaries. Learner transformation can be designed for by moving away from assessing courses, to assessing at the whole of graduate profile outcome level.

\section{FINAL THOUGHTS}

Steve: The programme served a purpose to provide a vehicle for sustainable practice learning and to embed transformation and resilience. What a ride! I am grateful to all the learners and OP staff who have enabled such difference in a programme to have a home. Transformational learning is now business as usual in Capable NZ but there's still much to do. The professional practice suite institutionalises the transformation needed for embedding sustainable practice right through the levels of learning from Bachelors to Doctorate.

Alexa: Bring it on.

It's interesting to see things we worked on and were interested in come full circle.

We burned out on communal food initiatives [because there were so many

of them in our project lists], but now they're everywhere.

The enduring nature of the relationships formed.

\begin{abstract}
Alexa Forbes is a learning facilitator at Capable NZ and is also an Otago Regional Councillor.
\end{abstract}
(D) https://orcid.org/0000-0002-2637-6925

Steve Henry is a learning facilitator at Capable NZ at Otago Polytechnic's College of Work-based Learning. He is acting programme lead for the Bachelor of Leadership for Change and facilitates in the professional practice suite. His doctoral research is focused on learner transformation in formal vocational education.

Email: steve.henry@op.ac.nz 


\section{REFERENCES}

Bochner, A., \& Ellis, C. (2016). Evocative autoethnography: Writing lives and telling stories. Routledge.

Durie, M. (1998). Whaiora: Maori health development. Oxford University Press.

Henry S., \& Forbes, A. (2017a). Development of the Centre for Sustainable Practice at Otago Polytechnic. Scope: Learning \& Teaching, 4, 38-45. https://www.thescopes.org/assets/Uploads/cl50294686/SCOPE-LearnTeach-4-5-Henry-Forbes.pdf

Henry S., \& Forbes, A. (2017b). Creating social infrastructure for Community led development in the Queenstown lakes district. Scope: Learning \& Teaching, 4, 53-77.

Ker, G. R. (2017). Degrees by Independent Learning: A case study of practice at Otago Polytechnic, Dunedin, New Zealand. (Doctoral thesis, Middlesex University, London, UK.).

Kimmerer, R. W. (n.d.). Skywoman Falling. Emergence Magazine. Retrieved 28 November 2021, from https://emergencemagazine. org/op_ed/skywoman-falling/

Lave, J., \& Wenger, E. (1991). Situated learning: Legitimate peripheral participation. Cambridge University Press.

Mann, S., Eden-Mann, P., Smith, L., Ker, G., Osborne, P., \& Alexander-Crawford, P. (2017). A transformation mindset as the basis for sustainable community development, 59-72. Paper presented at the International Conference of the Association of Community Development, Auckland. http://www.unitec.ac.nz/epress/wp-content/uploads/2017/07/ ACDA-IACD-2017-proceedings.pdf

Mezirow, J. E. (1997). Transformation theory: theory to practice. New Directions for Adult and Continuing Education, (74), 5-12.

Mezirow, J. (2000). Learning to think like an adult. Core concepts of transformation theory. In J. Mezirow and Associates, Learning as transformation. Critical perspectives on a theory in progress, 3-34. Jossey-Bass.

Otago Polytechnic (2008). A Simple Pledge. https://www.op.ac.nz/assets/Uploads/Sustainability/47f55b760a/A-Simple-PledgeDocument.pdf

Otago Polytechnic (2010). Graduate Diploma in Sustainable Practice programme handbook. Otago Polytechnic.

Schumacher, E, (200I). Small Is beautiful: a study of economics as if people mattered. Random House.

Sterling, S. (200I). Sustainable education: re-visioning learning and change. Schumacher Society Publishers. 